\title{
INVESTIGATION OF A THERMOELECTRIC COOLING SYSTEM BASED ON A PELTIER MODULE USING A TEMPERATURE CHAMBER
}

\author{
Kolber P.., Perczyński D.**, Peszyński K.***
}

\begin{abstract}
The article presents the results of testing the cooling system, the basic element of which is the Peltier module. The TEC1-12707 module was used in the test stand. An analysis of temperature values was carried out at various points in the deigned system, in particular in the temperature chamber (refrigerated space) on the cold side of the module. This analysis was performed in two variants with and without additional forced cooling of the warm side of the system. For the given system, the equation determining the transient state before reaching full heating capacity was derived.
\end{abstract}

Keywords: Peltier effect, Thermoelectric power generator, Refrigerated chamber, Joule heat, Transient state.

\section{Introduction}

The basic element used to build thermoelectric cooling systems is the Peltier module, usually composed of two parallel ceramic plates between which are alternately arranged semiconductors type "p" and " $n$ ". These semiconductors are electrically connected in series with copper plates.

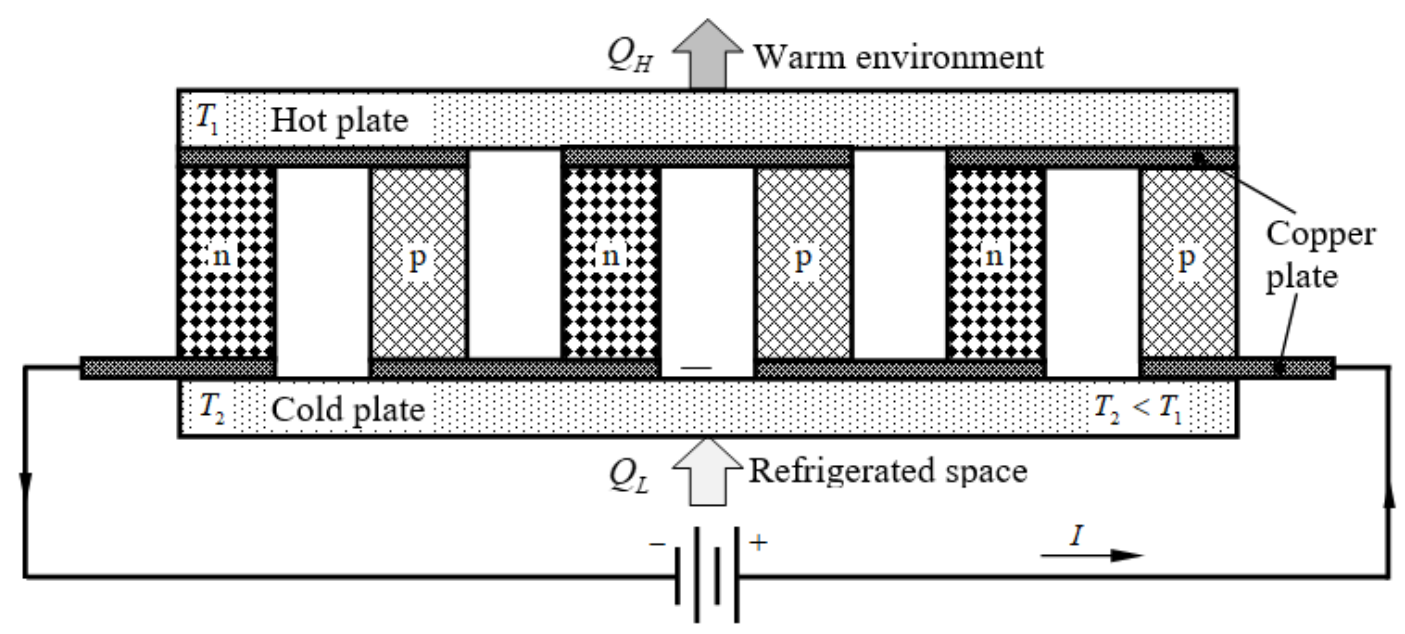

Fig. 1: Thermoelectric refrigerator (Peltier module).

As a result of absorbing energy in one joint and generating energy in the other, a difference in temperature arises between the joints. Heat is absorbed from the refrigerated space in the amount of $Q_{L}$ and rejected to the warmer environment in the amount of $Q_{H}$. The difference between these two quantities is the net electrical work that needs to be supplied; that is $W_{e}=Q_{H}-Q_{L}$. When current flows through the system, a certain amount of heat - Joule heating - also arises in the module itself due to electrical resistance.

\footnotetext{
Assist. Prof. Piotr Kolber, PhD.: Faculty of Mechanical Engineering, UTP University of Science and Technology, Al. prof. S. Kaliskiego 7, 85-789 Bydgoszcz, Poland, pkolber@utp.edu.pl

** Assist. Prof. Daniel Perczyński, PhD.: Faculty of Mechanical Engineering, UTP University of Science and Technology, Al. prof. S. Kaliskiego 7, 85-789 Bydgoszcz, Poland, perkol@utp.edu.pl

*** Assoc. Prof. Kazimierz Peszyński, PhD.: Faculty of Mechanical Engineering, UTP University of Science and Technology, Al. prof. S. Kaliskiego 7, 85-789 Bydgoszcz, Poland, peszyn@utp.edu.pl
} 


\section{Experimental setup}

The test stands were used to properties measurement of the cooling system, the basic element of which was the Peltier TEC1-12707 module with the following parameters: supply voltage $12 \mathrm{~V}$ (max $15.4 \mathrm{~V}$ ), current consumption $5 \mathrm{~A}(\max 7 \mathrm{~A})$, maximum power input $107.8 \mathrm{~W}$, maximum dissipated power $62 \mathrm{~W}$, $\Delta \mathrm{T}_{\max }=59^{\circ} \mathrm{C}, \Delta \mathrm{T}_{\min }=-135^{\circ} \mathrm{C}$, see Fig. 2. Aluminum radiators have been attached to both sides of the Peltier module for better heat exchange with the environment. The cold side of the module with the heat sink is placed in a specially constructed temperature chamber to limit the impact of the environment on the temperature values of the cooling cell. The heat sink attached to the warm side of the module was optionally subjected to forced cooling by a fan.

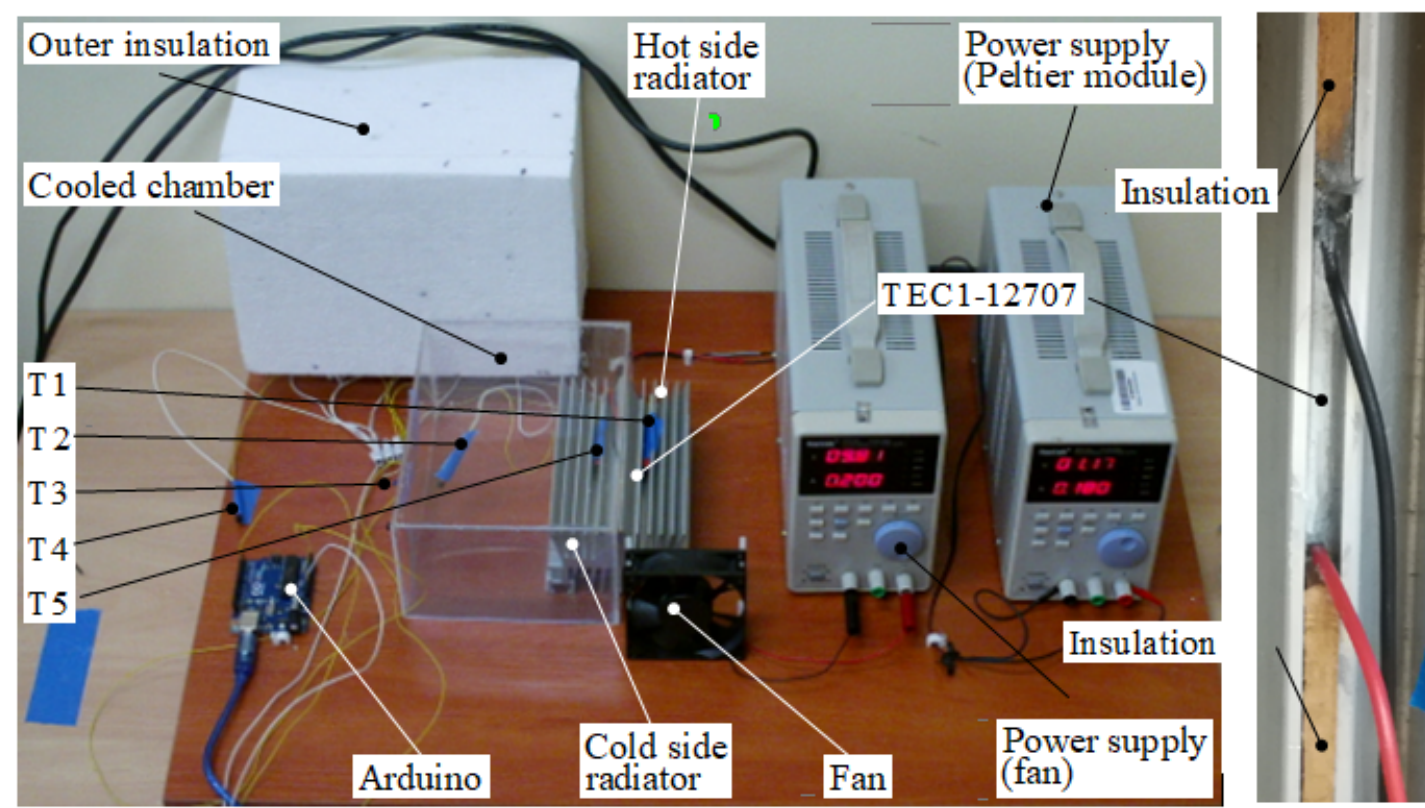

Fig. 2: General view of test stand.

Temperature measurements were carried out at five points (Fig. 3): T1 - on the cold side of the Peltier module, $\mathrm{T} 2$ - in the middle of the temperature chamber, T3 - at the inner wall of the temperature chamber housing T4 - outside the system (environment temperature), T5 - on the warm side of the Peltier module.

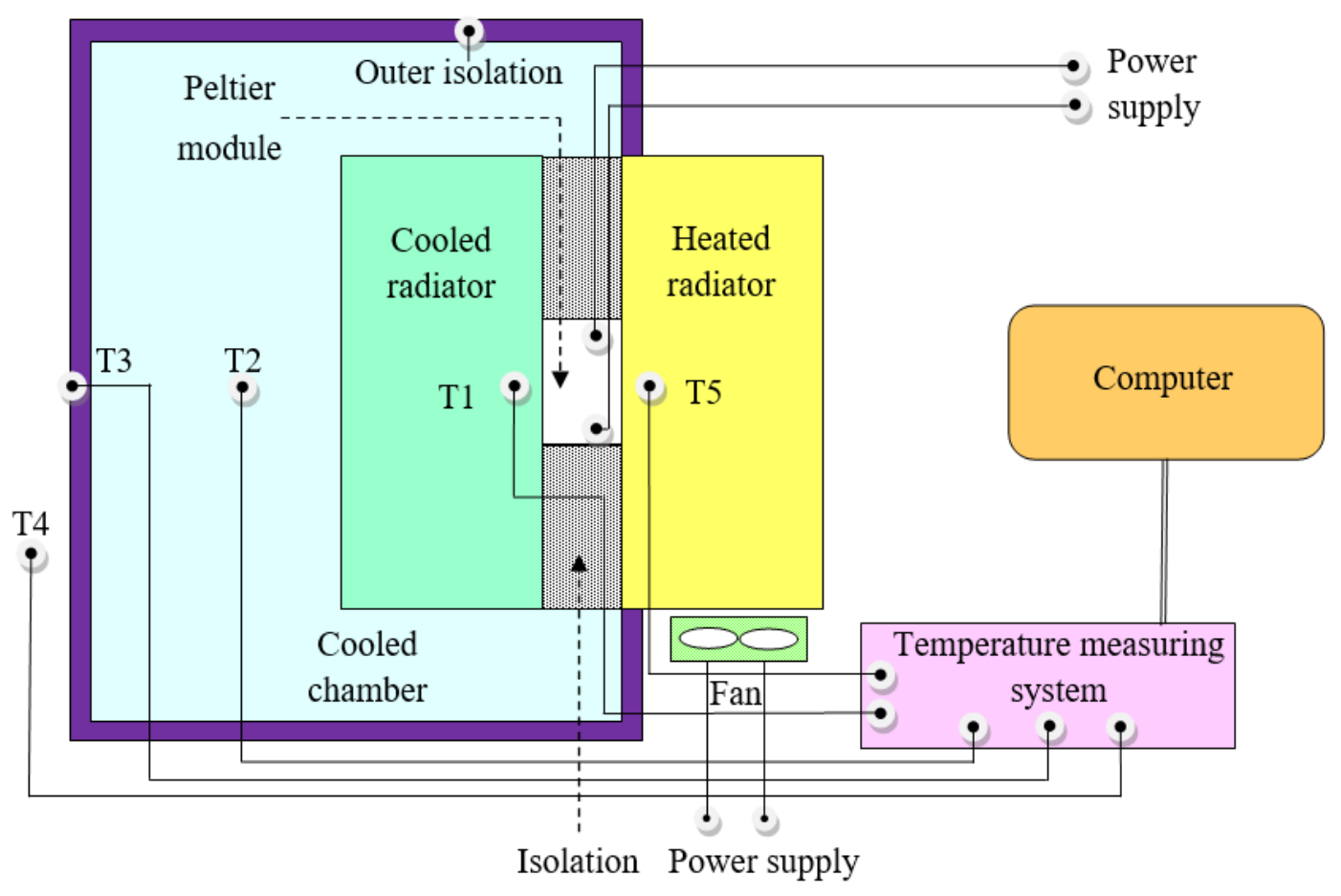

Fig. 3: General view of test stand. 
Measurements were made using DS18B20 digital temperature sensors using an ARDUINO microcontroller connected to a computer in which results from individual measuring points were recorded. The current for the Peltier module was controlled using the power supply device. The recording of measurements began after establishing relatively equilibrated temperature at individual measuring points and took place for a given value of the current.

\section{Investigation results}

Sample temperature charts at individual measuring points of the cooling system are shown in Fig. 4. Temperature measurements were carried out for two variants: a) without additional forced cooling of the warm side of the system, and b) with the use of cooling by fan.
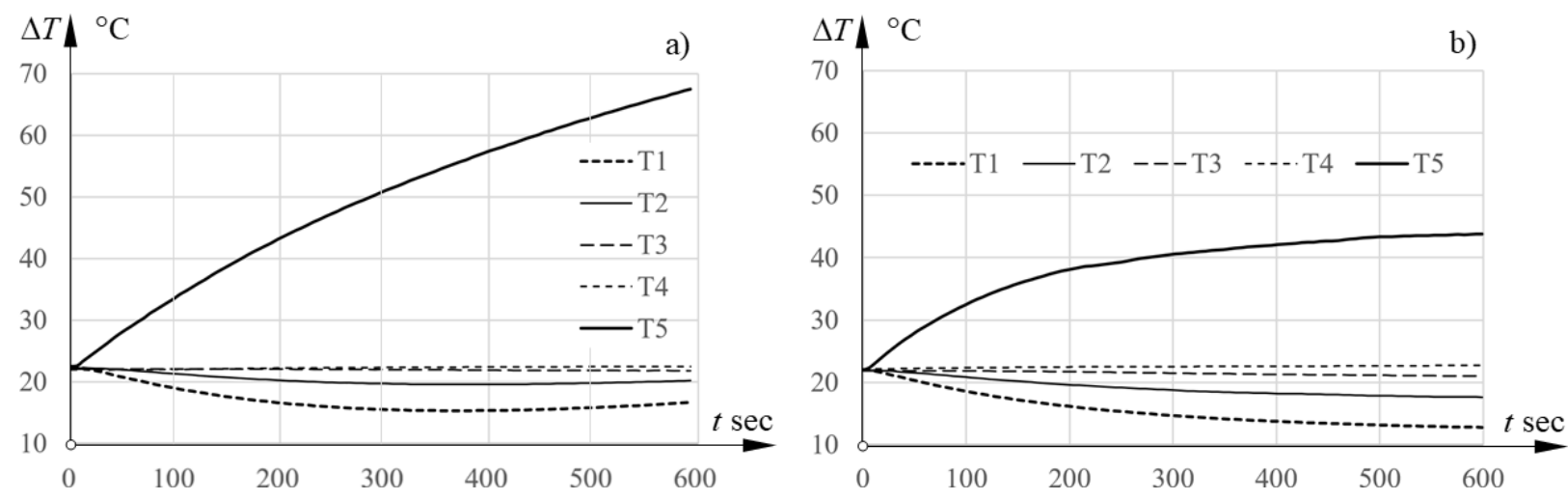

Fig. 4: Dynamic properties of Peltier module.

The analysis of Fig. 4a and Fig. 4b clearly shows that cooling the warm side of the Pelteira module (basically its radiator) significantly improves the cooling capacity of the module. Because the curve T1 illustrates the cooling properties of the module, it will be subject to additional analysis. First of all, the dynamic properties of the system were analyzed.

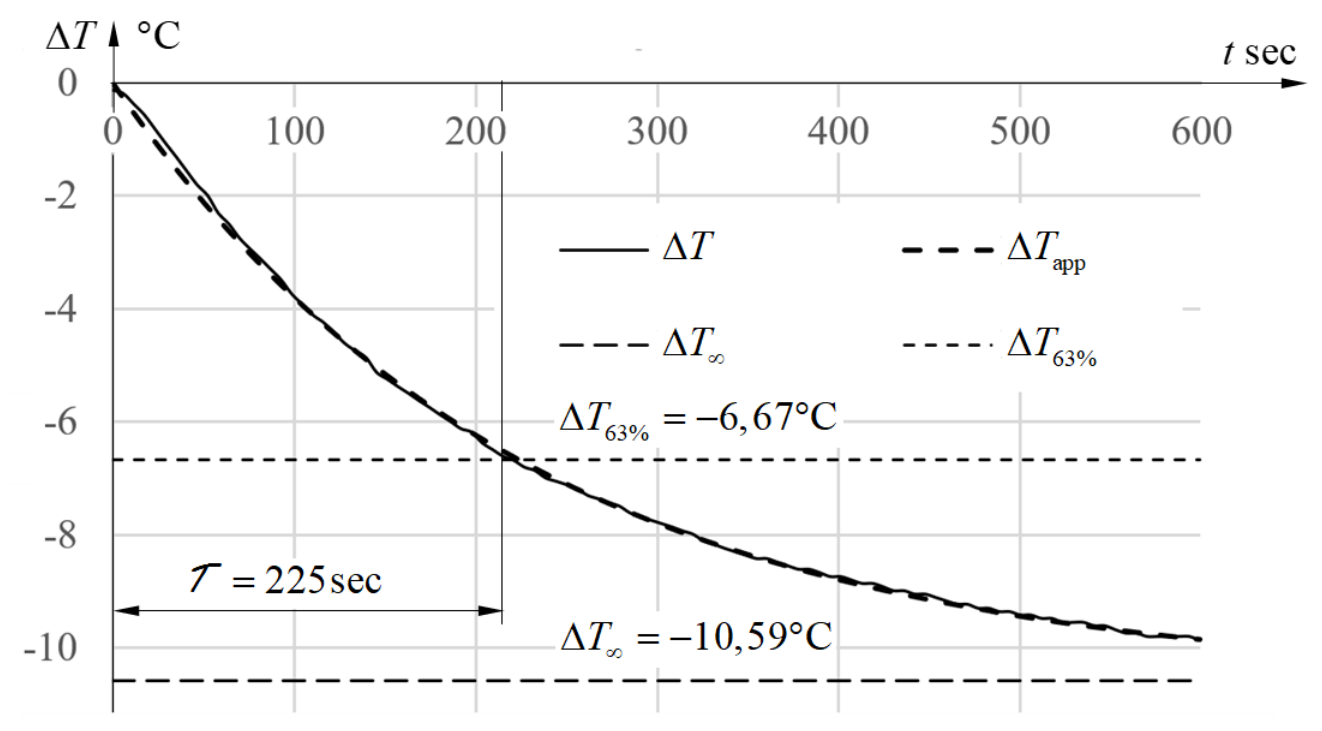

Fig. 5: Dynamic properties of Peltier module.

Based on the mass analysis of the Peltier module and the attached radiator, it can be seen that the system can be treated as a first order static object (one thermal capacity). The temperature $T_{1}$ should be treated as a parameter informing about how much the surface of the radiator has been cooled down in relation to the ambient temperature, therefore, Fig. 5 shows the dependence of the temperature drop over time $\Delta T=T_{1}-T_{4}=f(t)$. This is also justified by the fact that there is a slight difference in the temperature of the external wall of the cold chamber and the ambient temperature $T_{4} \cong T_{3}$. It proves that the external insulation fulfilled its task, i.e. good insulation from the surroundings. 
The first-order static object is described by the equation:

$$
\Delta T(t)=\Delta T_{\infty}\left(1-e^{-\frac{t}{T}}\right)
$$

where: $T$ is the time constant for the first order static system and $\Delta T_{\infty}$ is the steady state temperature. As a result of fitting the measured curve $\Delta T(t)$ to the Eq. (1) by means of optimization (minimization) of the objective function in the form of the sum of least squares, $T=225 \mathrm{~s}$ and was obtained $\Delta T_{\infty}=-10.59^{\circ} \mathrm{C}$, so that the approximating curve has form:

$$
\Delta T(t)=-10.59\left(1-e^{-\frac{t}{225}}\right)
$$

In industrial practice, it is assumed that steady state occurs after the expiration of $t_{\mathrm{st}}=3 T$, so that the system reaches its full capacity over time $t_{\mathrm{st}}=775 \mathrm{sec}$.

The temperature values achieved at individual measuring points after $600 \mathrm{sec}$ without and using forced cooling of the warm side of the hot side radiator by a fan for two values of the power supply are shown in Tab. 1.

Tab. 1: Measured values for different power supplies.

\begin{tabular}{|c|c|c|c|c|c|c|c|c|}
\hline Power supply & $\begin{array}{c}\mathrm{T} 1 \\
{\left[{ }^{\circ} \mathrm{C}\right]}\end{array}$ & $\begin{array}{c}\mathrm{T} 2 \\
{\left[{ }^{\circ} \mathrm{C}\right]}\end{array}$ & $\begin{array}{c}\mathrm{T} 3 \\
{\left[{ }^{\circ} \mathrm{C}\right]}\end{array}$ & $\begin{array}{c}\mathrm{T} 4 \\
{\left[{ }^{\circ} \mathrm{C}\right]}\end{array}$ & $\begin{array}{c}\mathrm{T} 5 \\
{\left[{ }^{\circ} \mathrm{C}\right]}\end{array}$ & $\begin{array}{c}P_{\mathrm{c}} \\
{[\mathrm{W}]}\end{array}$ & $\eta_{c}$ & $\begin{array}{c}\text { Cooling of hot } \\
\text { side }\end{array}$ \\
\hline $\mathrm{P}_{\mathrm{S}}=7.5 \mathrm{~W}$ & 15.4 & 19.4 & 22 & 22.8 & 37.2 & 6.1 & 0.93 & no \\
\hline $\mathrm{P}_{\mathrm{S}}=7.5 \mathrm{~W}$ & 15.1 & 20.1 & 21.7 & 22.7 & 30.2 & 6.8 & 0.91 & fan \\
\hline $\mathrm{P}_{\mathrm{S}}=40.25 \mathrm{~W}$ & 16.6 & 20.2 & 21.7 & 22.5 & 67.4 & 8.1 & 0.20 & no \\
\hline $\mathrm{P}_{\mathrm{S}}=40.25 \mathrm{~W}$ & 12.8 & 17.6 & 20.7 & 22.8 & 44.8 & 9.4 & 0.23 & fan \\
\hline
\end{tabular}

where: $P_{c}$ is cooling power, $\eta_{\mathrm{c}}$ is cooling efficiency designated in accordance with Kolber et all., (2018).

\section{Conclusions}

In the examined thermoelectric cooling system, a significant impact of forced additional cooling on the warm side of the radiator on the values of temperature achieved, was noticed.

The T1 curve in Fig. 4a confirms the harmful effects of Joule heat on system performance (efficiency). After approx. $350 \mathrm{sec}$, the $\mathrm{T} 1$ temperature reaches its minimum value and then, as a result of the release of harmful heat, increases.

Dynamic properties are very important from the point of view of system control (Sadowski et al., 2016). The control consists in changing the supply current under various conditions. In the assumed use of the tested device for cooling the car cabin, forced cooling can be replaced by the movement of air while driving.

\section{Acknowledgement}

The authors would like to kindly thank for institutional support BS 28/2018 granted by Faculty of Mechanical Engineering of UTP University in Bydgoszcz.

\section{References}

Kolber P., Perczyński D., Peszyński K. and Landowski B. (2018) Efficiency testing of thermoelectric cooling cell based on Peltier module. Engineering Mechanics 2018; 24; 1805-8248, ISBN: 978-80-86246-88-8, pp. 381-384.

Królicki Z. (2006) Basics Thermodynamic of Temperature Reduction. Oficyna wydawnicza Politechniki Wrocławskiej, Wrocław 2006 (in Polish).

Sadowski E., Kowalik R. and Pniewski R. (2016) The use of Peltier cells for the construction of refrigeration systems in transport (in Polish: Wykorzystanie ogniw Peltiera do budowy układów chłodzących w transporcie), Autobusy 12/2016, pp. 1335-1338. 